\title{
INTENTANDO DERRUMBAR MITOS: PARTIDOS Y SISTEMAS ELECTORALES EN ARGENTINA Y BRASIL
}

\section{Miguel Barrientos ${ }^{1}$}

Resumo: Os partidos brasileiros respondem a uma dinâmica regional, operando em determinados espaços do país? Os partidos argentinos se estruturam nacionalmente, ferindo o federalismo e esfumando as realidades provinciais? Até onde isso é verdade? O que acontece hoje nestes federalismos? Partidos, sistemas de partidos, sistemas eleitorais e fenômenos vinculados a estes (como a sobre-representação distrital e seu efeito sobre os partidos, etc.) em nível federal no Brasil e na Argentina se analisam no presente trabalho. Primeiramente, se faz um estudo dos sistemas eleitorais na esfera federal. Logo, realiza-se uma análise do sistema de partidos na arena nacional e acerca do que dizem as constituições (Constituição da República Federativa do Brasil, de 1988 CF88 -; e a Constitución de la Nación Argentina - CN94 -) sobre estes instrumentos do exercício democrático. Também se faz um estudo do presente dos partidos e a forma de classificá-los. O fenômeno da sobre-representação distrital (SRD), por sua vez, é objeto de uma profunda pesquisa, pela importância que cobra nestas federações. A forma em que as unidades federativas menores encontram-se sobre-representadas coloca um desafio aos estes federalismos, ao estabelecer pautas no jogo político federal.

Palavras-chave: constituintes partidos; sobre-representação distrital (SRD); Brasil; Argentina.

Resumen: ¿Los partidos brasileños responden a una dinámica regional, operando en ciertos espacios del país? ¿Los partidos argentinos se estructuran nacionalmente, hiriendo el federalismo y esfumando las realidades provinciales? ¿Hasta dónde esto es cierto? ¿Qué sucede hoy en estos federalismos? Partidos, sistemas de partidos, sistemas electorales y fenómenos vinculados a estos (como la sobre-representación distrital y su efecto sobre los partidos, etc.) en las esferas federales de Brasil y Argentina se analizan en el presente trabajo. Inicialmente, se realiza un estudio de los sistemas electorales a nivel federal. Luego, se produce un análisis del sistema de partidos en la arena nacional y sobre lo que expresan las constituciones (Constituição da República Federativa do Brasil, de 1988 -CF88; y la Constitución de la Nación Argentina -CN94) sobre estos instrumentos de ejercicio democrático. También se realiza un estudio sobre el presente de los partidos y la forma de clasificarlos. El fenómeno de la sobre-representación distrital (SRD) también es objeto de investigación, por la importancia que cobra en estas federaciones. La forma en que las unidades federativas menores se encuentran sobre-representadas coloca un desafío a estos federalismos: establece pautas del juego político federal.

Palabras-clave: partidos; sobre-representación distrital (SRD); Brasil; Argentina.

Abstract: Do Brazilian parties play with a regional dynamic, working in specific geographical places? Are Argentinean parties structured in a national way, destroying the federal and provincial realities? Are these thinks true? What happen with these Federations today? Parties, party systems, electoral systems and phenomena connected with these things (like malapportionment and its effects on the parties, etc.) in Brazil and Argentina federal arenas, are analyzed in the present paper. First, I make a study of electoral systems in federal level. Then, I make an analysis of party systems in the national arena and the constitutional texts (1998 Constituição da República Federativa do Brasil - CF88 -; and 1994 Constitución de la Nación Argentina - CN94 -). Also, I study the present situation of the political parties and its classification. Malapportionment (SRD) phenomenon is object of a research, because its relevance in federal countries. The over-representation of the little federative units is a challenge to these federalisms, establishing rules in the federal political game.

Key-words: parties; malapportionment (SRD); Brazil; Argentina.

\footnotetext{
${ }^{1}$ Lic. en Ciencia Política por la Universidad de Buenos Aires, Mestre em Ciência Política por la Universidade Federal do Rio Grande do Sul y Doctorando en C. Política de la Universidade de São Paulo. Contacto: miguelbarrientos@usp.br. El autor agradece la lectura atenta del trabajo y los consejos dados por Bruno Bolognesi (Universidade Federal de São Carlos).
} 


\section{SISTEMAS ELECTORALES A NIVEL FEDERAL}

Existen varios puntos de contacto entre los federalismos de Brasil y Argentina. Por ejemplo, en la composición del Ejecutivo y del Legislativo federal. La elección de sus Presidentes se establece por medio de una mayoría especial que, cuando no es alcanzada en primera vuelta, debe ser lograda en la segunda vuelta electoral: en Brasil, por un sistema de ballotage típico; en Argentina, a través del "ballotage atenuado". También en ambos se eligen tres representantes por distrito para el Senado Federal do Brasil y el Senado de la Nación argentino. Pero, mientras que en Argentina la elección es por "sistema de lista incompleta" (dos senadores para el partido más votado y el otro para el segundo partido), en Brasil el sistema es mayoritario3. Para la elección de representantes que componen la Cámara de Diputados, Brasil y Argentina cuentan con fórmulas proporcionales.

También, ambos poseen sistemas de representación proporcional, en los que cada partido presenta candidatos, los electores votan en el partido y éste obtiene bancas, siguiendo un cálculo proporcional a los votos obtenidos. En Brasil, los 513 deputados federais son electos en 27 distritos plurinominales de magnitud variable. Se utiliza la fórmula de cociente electoral, y no existe cláusula de barrera legal ni renovación de la Câmara dos Deputados por mitades (LEGISLATINA, 2003b, 1). El sistema de representación proporcional con barreras bajas y distritos de gran tamaño alienta una alta fragmentación (MAINWARING; SHUGART, 1997, 79). Brasil no cuenta con cláusula de barrera legal, entonces la fragmentación es aún mayor. En Argentina, para la elección para la Cámara de Diputados de la Nación, están en juego 257 bancas en 24 circunscripciones plurinominales, de tamaño variable. Aquí, la aplicación de la fórmula D’Hondt, la renovación por mitades de la cámara y la cláusula de barrera legal de $3 \%$ del total de electores de cada distrito, hacen que la proporcionalidad aparezca atenuada por magnitudes de distrito mucho más bajas que en el caso brasileño (ABAL MEDINA (h); SUÁREZ CAO; NEJAMKIS, 2002).

\footnotetext{
${ }^{2}$ Si una de las fórmulas obtiene más del $45 \%$ de los votos, o $40 \%$ con una diferencia de 10 puntos porcentuales en relación a la segunda candidatura más votada, esta será considerada victoriosa y sus integrantes consagrados como Presidente y Vice-Presidente (art. $97^{\circ}$ y $98^{\circ}$ de la CN94). 3 Cambiando el voto según el número de cargos, dependiendo si la elección es para renovación de un tercio del Senado -en ese caso, es elección uninominal por mayoría simple- o para renovación de dos tercios aquí, elección binominal.
} 
Tabla 1. Argentina. Magnitud distrital para la Cámara federal

\begin{tabular}{|c|c|c|c|}
\hline Posición & Unidad Federativa & $\begin{array}{c}\text { Mag } \\
\mathbf{n}\end{array}$ & $\begin{array}{c}\text { \% sobre } \\
\text { total }\end{array}$ \\
\hline $1^{\circ}$ & Buenos Aires (BUE) & 70 & $\mathbf{2 7 , 2 4 \%}$ \\
\hline $2^{\circ}$ & C. A. de Buenos Aires (CABA) & 25 & $\mathbf{9 , 7 3 \%}$ \\
\hline $3^{\circ}$ & Santa Fe (SFE) & 19 & $7,39 \%$ \\
\hline $4^{\circ}$ & Córdoba (CBA) & 18 & $7,00 \%$ \\
\hline $5^{\circ}$ & Mendoza (MZA) & 10 & $3,89 \%$ \\
\hline $6^{\circ}$ & Tucumán (TUC) & 9 & $\mathbf{3 , 5 0 \%}$ \\
\hline $7^{\circ}$ & Entre Ríos (ERI) & 9 & $\mathbf{3 , 5 0 \%}$ \\
\hline $8^{\circ}$ & Salta (SAL) & 7 & $2,72 \%$ \\
\hline $9^{\circ}$ & Chaco (CHA) & 7 & $\mathbf{2 , 7 2 \%}$ \\
\hline $10^{\circ}$ & Misiones (MIS) & 7 & $2,72 \%$ \\
\hline $11^{\circ}$ & Corrientes (COR) & 7 & $2,72 \%$ \\
\hline $12^{\circ}$ & Santiago del Estero (SGO) & 7 & $2,72 \%$ \\
\hline $13^{\circ}$ & San Juan (SJU) & 6 & $\mathbf{2 , 3 3 \%}$ \\
\hline $14^{\circ}$ & Jujuy (JUJ) & 6 & $\mathbf{2 , 3 3 \%}$ \\
\hline $15^{\circ}$ & Río Negro (RNO) & 5 & $\mathbf{1 , 9 5 \%}$ \\
\hline $16^{\circ}$ & Formosa (FOR) & 5 & $\mathbf{1 , 9 5 \%}$ \\
\hline $17^{\circ}$ & Neuquén (NEU) & 5 & $1,95 \%$ \\
\hline $18^{\circ}$ & Chubut (CHU) & 5 & $\mathbf{1 , 9 5 \%}$ \\
\hline $19^{\circ}$ & San Luis (SLU) & 5 & $\mathbf{1 , 9 5 \%}$ \\
\hline $20^{\circ}$ & Catamarca (CAT) & 5 & $\mathbf{1 , 9 5 \%}$ \\
\hline $21^{\circ}$ & La Pampa (LAP) & 5 & $\mathbf{1 , 9 5 \%}$ \\
\hline $22^{\circ}$ & La Rioja (LRJ) & 5 & $\mathbf{1 , 9 5 \%}$ \\
\hline $23^{\circ}$ & Santa Cruz (SCR) & 5 & $\mathbf{1 , 9 5 \%}$ \\
\hline \multirow[t]{2}{*}{$24^{\circ}$} & Tierra del Fuego (TDF) & 5 & $\mathbf{1 , 9 5 \%}$ \\
\hline & Total Argentina & $\mathbf{2 5 7}$ & $100,00 \%$ \\
\hline
\end{tabular}

Fuente: Elaboración propia en base a Dirección Nacional Electoral (2009).

\section{Tabla 2. Brasil. Magnitud distrital} para la Câmara federal

\begin{tabular}{|c|c|c|c|}
\hline Posición & Unidad Federativa & $\begin{array}{c}\text { Mag } \\
\mathbf{n}\end{array}$ & $\begin{array}{c}\% \text { sobre } \\
\text { total }\end{array}$ \\
\hline $1^{\circ}$ & São Paulo (SP) & 70 & $13,65 \%$ \\
\hline $2^{\circ}$ & Minas Gerais (MG) & 53 & $10,33 \%$ \\
\hline $3^{\circ}$ & Rio de Janeiro (RJ) & 46 & $\mathbf{8 , 9 7 \%}$ \\
\hline $4^{\circ}$ & Bahia (BA) & 39 & $7,60 \%$ \\
\hline $5^{\circ}$ & Rio Grande do Sul (RS) & 31 & $6,04 \%$ \\
\hline $6^{\circ}$ & Paraná (PR) & 30 & $5,85 \%$ \\
\hline $7^{\circ}$ & Pernambuco (PE) & 25 & $4,87 \%$ \\
\hline $8^{\circ}$ & Ceará (CE) & 22 & $4,29 \%$ \\
\hline $9^{\circ}$ & Maranhão (MA) & 18 & $\mathbf{3 , 5 1 \%}$ \\
\hline $10^{\circ}$ & Pará (PA) & 17 & $3,31 \%$ \\
\hline $11^{\circ}$ & Goiás (GO) & 17 & $3,31 \%$ \\
\hline $12^{\circ}$ & Santa Catarina (SC) & 16 & $3,12 \%$ \\
\hline $13^{\circ}$ & Paraíba (PB) & 12 & $2,34 \%$ \\
\hline $14^{\circ}$ & Espírito Santo (ES) & 10 & $\mathbf{1 , 9 5 \%}$ \\
\hline $15^{\circ}$ & Piauí (PI) & 10 & $\mathbf{1 , 9 5 \%}$ \\
\hline $16^{\circ}$ & Alagoas (AL) & 9 & $1,75 \%$ \\
\hline $17^{\circ}$ & Amazonas (AM) & 8 & $\mathbf{1 , 5 6 \%}$ \\
\hline $18^{\circ}$ & $\begin{array}{l}\text { Rio Grande do Norte } \\
\text { (RN) }\end{array}$ & 8 & $1,56 \%$ \\
\hline $19^{\circ}$ & Mato Grosso (MT) & 8 & $1,56 \%$ \\
\hline $20^{\circ}$ & Mato Grosso do Sul (MS) & 8 & $1,56 \%$ \\
\hline $21^{\circ}$ & Distrito Federal (DF) & 8 & $1,56 \%$ \\
\hline $22^{\circ}$ & Sergipe (SE) & 8 & $\mathbf{1 , 5 6 \%}$ \\
\hline $23^{\circ}$ & Rondônia (RO) & 8 & $\mathbf{1 , 5 6 \%}$ \\
\hline $24^{\circ}$ & Tocantins (TO) & 8 & $\mathbf{1 , 5 6 \%}$ \\
\hline $25^{\circ}$ & Acre (AC) & 8 & $\mathbf{1 , 5 6 \%}$ \\
\hline $26^{\circ}$ & Amapá (AM) & 8 & $1,56 \%$ \\
\hline $27^{\circ}$ & Roraima (RR) & 8 & $1,56 \%$ \\
\hline & Total Brasil & 513 & $100,00 \%$ \\
\hline
\end{tabular}

Fuente: Elaboración propia en base a Tribunal Superior Eleitoral (2009).

\section{PARTIDOS Y SISTEMAS DE PARTIDOS A NIVEL FEDERAL}

Tanto la CN94 como la CF88 dan preponderancia a los partidos políticos como institutos válidos para el ejercicio de la democracia representativa. El artículo 38 de la CN94 define que los partidos políticos son instituciones fundamentales del sistema democrático argentino. Por su parte, el art. $14 \S 3^{\mathrm{o}} \mathrm{V}$ de la CF88 establece, como condición de elegibilidad, la afiliación a un partido político, y el art. 17 de esta misma Carta considera libre la creación, fusión, incorporación y extinción de partidos 
políticos, siempre que sean resguardados, entre otros, la soberanía nacional, el régimen democrático y el pluripartidismo.

En relación a los partidos argentinos, se encuentra una diferenciación entre dos tipos. Existen "partidos de distrito" y "partidos nacionales". El "distrito" es cada una de las circunscripciones electorales y, como en el caso brasileño, este se corresponde con el territorio de las unidades federativas. Así, los "partidos de distrito" son agrupaciones políticas que solicitaron su reconocimiento ante el juez electoral, y cumplen con ciertos requisitos establecidos en la Ley Orgánica de los Partidos Políticos (Ley No 23.298). Los "partidos nacionales" no son sino "partidos de distrito" reconocidos que decidieron lanzarse al juego político más allá del distrito de origen, resolviendo actuar en cinco o más distritos bajo el mismo nombre, principios, programa y bases, como partido nacional (LEGISLATINA, 2003a, 9). La importancia de los "partidos de distrito" no es menor, siendo que, en cantidad de electores afiliados, estos partidos representan el 12,48\% del total nacional de afiliados.

En el caso brasileño, son considerados "partidos políticos" los agrupamientos de carácter nacional, habiendo logrado el apoyo electoral de, por lo menos, el o,5\% de los votos válidos en la última elección general para la Câmara dos Deputados, distribuidos en un tercio o más de los Estados, con un mínimo de 0,1\% de votos en cada distrito, según establece la Lei dos Partidos Políticos (Lei Nº 9096/95). La explicitación del carácter nacional, obviamente, no contempla, como en el sistema argentino, la posibilidad de "partidos de distrito".

El análisis de Stepan (1999) sobre los sistemas de partidos políticos en países federales es relevante. El autor estudia el grado de nacionalización del sistema partidario en sus orientaciones y en los sistemas de incentivos. La relación que establece es que cuanto más disciplinados sean los partidos y cuanto más privilegien intereses del conjunto de la sociedad en detrimento de intereses locales, más los partidos nacionales tienen condiciones de atenuar las características limitantes del federalismo. Stepan considera que, si los partidos nacionales son muy disciplinados y cuentan con una fuerte estructura organizacional, entonces el sistema de partidos funcionará como una fuerza centralizadora al interior de una federación mononacional. Al contrario, si el sistema político no tiene un sistema de representación proporcional por lista abierta ni distritos uninominales con primarias partidarias, si los candidatos financian independientemente sus campañas, y si el sistema es presidencialista, entonces habrá muy pocos incentivos para que se cree una unidad partidaria nacional. Stepan coloca a Brasil en este último grupo, y Argentina puede incluirse también aquí. A continuación, se presenta un panorama de la historia y del momento actual que viven los partidos políticos en Argentina y Brasil. 


\subsection{PRESENTE DE LOS PARTIDOS ARGENTINOS}

Algunos meses antes de la última vuelta a la democracia (1983), los cinco principales partidos políticos volvieron a operar: la UCR, el PJ, el Partido Intransigente (PI), el Partido Demócrata Cristiano (PDC) y el Movimiento de Integración y Desarrollo (MID). Con las elecciones generales de 1983, comenzó el período democrático caracterizado por la fuerte presencia de los dos mayores partidos: la Unión Cívica Radical (UCR) y el Partido Justicialista (PJ) pasaron no sólo a dominar el espectro político, sino que, por años, estarían presentes en el proceso de socialización social de los argentinos. Históricamente, las bases socio-económicas de la UCR fueron las clases medias y las bases del PJ fueron las clases trabajadoras. A pesar de que estas asociaciones se han mantenido hasta el presente, ambos son considerados "partidos catch-all”, cuyas posiciones políticas oscilan alrededor del centro del espectro político.

Importante fue 1993, cuando tuvo lugar el "Pacto de Olivos" que, aunque haya servido para la Reforma Constitucional de 1994 y la subsecuente reelección de Menem, también significó el quiebre del bipartidismo argentino, con la organización de una tercera fuerza: Frente Grande (FG, después Frente País Solidario, FREPASO). En las presidenciales de 1995, este partido escaló al segundo lugar, obteniendo el 29,30\% de los votos, y enviando a la UCR a una lejana tercera posición por primera vez en su historia. Para terminar con la hegemonía de Menem, estos dos partidos se unieron en 1997 para crear la Alianza para el Trabajo, la Justicia y la Educación (ALIANZA). Esta coalición tuvo un buen desempeño en ese año, y mejor aún fue 1999, cuando venció las elecciones presidenciales. Pero, la coyuntura socio-económica y política no fue favorable al nuevo gobierno y, sumadas las peleas internas, una Argentina colapsada provocó el fin de la ALIANZA en 2001. El sistema de partidos no fue ajeno al caos y se fragmentó: corrientes internas del PJ y de la UCR formaron nuevas agrupaciones, que aún hoy gravitan en la arena política. Las elecciones de 2003 evidenciaron estos cambios: hubo cinco candidatos con más del 14\% de los votos, algo inédito en el país. Una UCR diezmada se vio superada en votos por las nuevas estructuras políticas nacidas en su interior, Afirmación para una República Igualitaria (ARI) y Recrear para el Crecimiento (RECREAR). El PJ vio la presentación de tres candidatos presidenciales afiliados al partido, utilizando agrupamientos ad hoc como el Frente para la Victoria (FpV, llevando a Néstor Kirchner como candidato), el Frente por la Lealtad (FpL, con fórmula encabezada por Menem) y el Frente Movimiento Popular (FMP, con Adolfo Rodríguez Saá como candidato). 
Afirmar que el sistema argentino es simple y bipartidario, por la importancia que tiene la elección para Presidente y Vice-Presidente, no se adapta a la realidad (CALVO et al., 2001, 67). No se puede tener una idea de la complejidad del sistema electoral y partidario argentino a través de la cantidad de partidos compitiendo en las elecciones. La Cámara Nacional Electoral registra que Argentina posee 686 partidos políticos reconocidos, de los cuales 33 son "partidos nacionales" y los restantes 653 son clasificados como "partidos de distrito" (CÁMARA NACIONAL ELECTORAL, 2008, 2).

Para De Luca, Jones y Tula (2002), en Argentina se observan cuatro tipos diferentes de partidos políticos que operan desde el retorno a la democracia, según el origen y la fuerza electoral. En primer lugar, aparecen los "partidos tradicionales", quienes dominaron el espectro político desde la segunda postguerra: el PJ y la UCR. Estos poseen alto grado de competencia interna para la selección de candidatos y una eficiente estructura territorial en todo el país. En segundo lugar, están las "terceras fuerzas", partidos que nacen y tienen excelentes desempeños electorales. Normalmente, operan en los mayores distritos, pero no logran institucionalizarse nacionalmente; así, cuando sufren un declive electoral, tienden a desaparecer y ven su espacio ocupado por otro partido de la misma especie. Entre estos, pueden ser citados la UCeDé, el FG/FREPASO, Acción por la República (AR), el Movimiento por la Dignidad y la Independencia (MODIN), entre otros. En la actualidad, se incluyen el ARI y la Propuesta Republicana (PRO). En tercer lugar, aparecen los "partidos provinciales", que responden a un líder fuerte y operan en un único distrito, en el que se tornan partido de gobierno o principal fuerza de oposición. Pueden tener origen en los "partidos de notables" locales; ser desagregaciones del PJ o de la UCR creadas a partir de discrepancias con las estructuras partidarias federales; o haber sido creados por los militares que gobernaron el distrito en la última dictadura (1976-83). Ejemplos son el Movimiento Popular Neuquino (MPN- NEU), el Movimiento Popular Fueguino (MOPOF- TDF), la Fuerza Republicana (FR- TUC), la Acción Chaqueña (ACH- CHA) y el Pacto Autonomista Liberal (PAL- COR). Finalmente, se encuentran los "partidos minoritarios", que son aquellos con escasa relevancia electoral, como el Partido Comunista (PC) y el Partido Obrero (PO).

Hoy, Argentina cuenta con un sistema multipartidario moderado, con bajo nivel de polarización ideológica y competencia interpartidaria centrípeta. Sin embargo, 
el PJ continúa ocupando una posición preponderante. Véase el Número Efectivo de Partidos (NEP4) en la Cámara, entre 1983 y 2007.

Tabla 3. Argentina. NEP en la Câmara

\begin{tabular}{lccccccc}
\hline \hline & $\mathbf{1 9 8 3}$ & $\mathbf{1 9 8 7}$ & $\mathbf{1 9 9 1}$ & $\mathbf{1 9 9 5}$ & $\mathbf{1 9 9 9}$ & $\mathbf{2 0 0 3}$ & $\mathbf{2 0 0 7}$ \\
\hline \hline Argentina & 2,19 & 2,75 & 3,15 & 2,86 & 3,45 & 3,48 & 3,65 \\
\hline Fuente: Rodríguez (2007). & & & & &
\end{tabular}

Conforme con Calvo (2005), frente al PJ hegemónico, se observa una UCR debilitada a nivel federal, pero que aún logra administrar municipios y Provincias, además de otros partidos que no logran establecer una propuesta común. También se cree que se pueden estar formando dos grandes grupos ideológicos, uno de centroderecha y otro de centro-izquierda, algo similar a los actuales sistemas chileno e italiano. Por otro lado, aún no puede ser descartada una volta al bipartidismo que efectivamente imperó entre 1983 y 1993 (MOCCA, 2009). Esto se debe a que, los únicos partidos que cuentan con buenas estructuras en todo el territorio son los dos partidos tradicionales, lo que genera que el sistema de partidos continúe "pivotando" en torno a ellos (BULCOURF; JOLÍAS, 2007, 71).

\subsection{PRESENTE DE LOS PARTIDOS BRASILEÑOS}

Antes de las elecciones de 1982, el régimen daba fin al bipartidismo constitucionalizado 5 , para fragmentar a la oposición. Exceptuando poquísimos partidos de izquierda, ninguna agrupación política del período 1946-1964 logró sobrevivir al último gobierno de facto (1964-85). Para 1985, el espectro político estaba formado también por el Partido do Movimento Democrático Brasileiro (PMDB, secuencia natural del MDB), el Partido Democrático Social (PDS, continuidad del ARENA), el Partido Democrático Trabalhista (PDT), y el Partido da Frente Liberal (PFL). A partir de ese momento, el sistema pasa a ser un pluripartidismo fragmentado: ningún partido logra, sólo, conquistar la mayoría de los cargos legislativos; por eso se tornan tan necesarias las alianzas de gobierno (ROMA; BRAGA, 2002, 76). Véase, en la Tabla Nº 4, el NEP en la Câmara dos Deputados, entre 1982 y 2010.

\footnotetext{
4 Se utiliza aquí el clásico indicador de Laakso y Taagepera, para medir el grado de fragmentación del sistema de partidos. Consiste en la siguiente fórmula: $\mathbf{N E P}=\mathbf{1} / \Sigma \mathbf{P}^{\mathbf{2}}$, donde P representa la proporción de bancas por partido (en las arenas legislativas) o la cantidad de votos (para elecciones mayoritarias). Así, no se tiene en cuenta sólo la cantidad de partidos que compiten, sino también su importancia relativa. En esta investigación, los NEP fueron obtenidos de fuentes secundarias, debidamente citadas.

5 Durante el Régimen Militar, se consagró en la práctica un sistema de partidos bipartidario: los militares controlaban el juego desde la Aliança Renovadora Nacional (ARENA), mientras que la oposición se aglutinaba en el Movimento Democrático Brasileiro (MDB).
} 
Tabla 4. Brasil. NEP en la Câmara dos Deputados $198219861990199419982002 \quad 2006 \quad 2010$

\begin{tabular}{lllllllll}
\hline \hline Brasil & 2,4 & 2,8 & 8,7 & 8,1 & 7,1 & 8,5 & 9,3 & 10,4
\end{tabular}

Fuente: Elaboración propia en base a datos de Tribunal Superior Eleitoral (2010)

\subsubsection{CLASIFICACIÓN DE LOS PARTIDOS POLÍTICOS BRASILEÑOS}

Interesante es el análisis de Peres (2002), relacionado con las visiones escépticas sobre Brasil en la redemocratización. "El reciente período democrático brasileño ha sido tomado como resultado de la combinación del peor de los mundos posibles: partidos pragmáticos y atomizados con representación proporcional” (PERES, 2002, 18 -traducción propia). Si esto último es visible mirando el NEP en la cámara baja federal, la estabilidad política alcanzada por Brasil en los últimos años refuta toda reflexión catastrófica sobre el país.

La propagación de agrupamientos políticos hace que, a primera vista, autores como Cardozo (2008) entiendan el sistema brasileño como basado en partidos débiles, poco institucionalizados y poco arraigados en la sociedad civil. En este punto, Kinzo (1993) considera que se deben hacer algunas excepciones. Para esta intelectual, como mínimo, los partidos más importantes (PMDB, PFL, PSDB, PPR, PT, PDT y PTB) han tomado posiciones diferenciadas. "Aunque la cohesión interna todavía es precaria en la mayoría de los partidos y a pesar de la fuerte fragmentación característica del sistema partidario, ya existen algunos espacios ideológico-partidarios capaces de balizar la lucha político-electoral” (KINZO, 1993, 96 -traducción propia).

En la actualidad, usando la clasificación de los partidos brasileños que Figueiredo y Limongi (1999) hacen, se pueden ver tres grandes espacios ideológicos: derecha, centro e izquierda. Haciendo una actualización de esta lista a las elecciones de 2010, se encuentra el siguiente panorama. A la derecha, entre otros, aparece el Partido Progressista (PP); los Democratas (DEM, ex- PFL); el Partido da República (PR); el PTB. En el centro, se localizan dos partidos de gran relevancia: el PMDB y el Partido da Social Democracia Brasileira (PSDB). Y, en la izquierda del espectro político, se encuentran el Partido dos Trabalhadores (PT); el Partido Democrático Trabalhista (PDT); el PCdoB; el Partido Verde (PV); el Partido Socialista dos Trabalhadores Unificado (PSTU); etc. Se suma aquí el Partido Socialismo e Liberdade (PSOL, cisma del PT).

Es evidente que, aunque exista una proliferación de partidos políticos, no todos alcanzan la misma relevancia ni consiguen perdurar elección tras elección, habiendo fusiones y desapariciones en todo el período contemporáneo de redemocratización. Se puede decir ahora que Brasil cuenta con tres tipos de partido. 
Primero, están los "grandes partidos", que poseen buenas performances electorales y cuentan con estructuras nacionales visibles. Entre estos, hay un núcleo estable formado por el PMDB, el PFL, el PP, el PT y el PDT, partidos con gran continuidad electoral a lo largo de las últimas dos décadas. A estos se suma el PSDB -desprendimiento del PMDB, creado en 1988-, con buen desempeño en las últimas elecciones. Finalmente, también se puede sumar el PTB, el cual tuvo mayor presencia, pero hoy se muestra en declive. En segundo lugar aparecen los "partidos pequeños y medianos", que gravitan en la política regional o estadual y aún no logran desarrollar fuerte penetración en la arena federal. Entre estos, aparecen el PCdoB, el PSOL, el PV, etc. Por último, se encuentran los "flash parties", agrupamientos creados para fomentar la candidatura de su líder o pequeño grupo dirigente, y que pueden llegar a obtener buenos desempeños, pero que tienden a desaparecer. Krause y Paiva (2002) encuentran al PRN de Collor (con óptima performance en 1990) como un partido que se adapta a esta última estrategia.

Cuando se observa el NEP en los últimos 20 años, es evidente la presencia de un multipartidismo firme. Bulcourf y Jolías (2007) consideran que Brasil está pasando por una institucionalización de su sistema de partidos, asumiendo la forma de pluralismo moderado, con orientación al gobierno, esto dado fundamentalmente por el acceso a recursos públicos.

\section{TERRITORIALIZACIÓN Y NACIONALIZACIÓN DEL VOTO}

Por el precepto de robustez del federalismo (MAINWARING, SAMUELS, 1997), se espera que el sistema político se estructure, no en torno al gobierno central, sino alrededor del nivel subnacional, teniendo a estos gobiernos como ejes del juego político. ¿Qué sucede con relación al voto en elecciones nacionales y cómo este se estructura en ambos países? Durante mucho tiempo, estudios en Argentina y Brasil reflexionaban sobre la distribución del voto en las elecciones nacionales. Entre los cientistas políticos brasileños, era casi unánime que el país estructuraba sus elecciones según patrones regionales; en Argentina, se entendía que el voto podía ser establecido según criterios nacionales, "ahogado" por los partidos tradicionales (PJ y UCR). Elecciones en ambos países en los últimos años han demostrado que estas instituciones similares pueden tener comportamientos diferentes (ABAL MEDINA; SUÁREZ CAO; NEJAMKIS, 2002). Estos países parecen recorrer caminos inversos: si en Argentina, se pasa de un sistema bipartidario con organizaciones fuertes y disciplinadas a otro, multipartidario con organizaciones más débiles; Brasil recorre el camino inverso, desde un sistema con altísimo NEP, y partidos débiles, personalistas y "de alquiler", a un 
sistema más estable, con mayor fidelidad partidaria. Lo que se intentará ver es si también ambos países tienen trayectorias opuestas con relación al voto y su estructuración geográfica, siguiendo las elecciones nacionales recientes.

\subsection{GEOGRAFÍA Y VOTO EN LA ULLTIMA DÉCADA ARGENTINA}

El período que se prolonga entre la salida de De la Rúa (dic. de 2001) y la pose de Kirchner (mayo de 2003) mostró una profundización en la federalización del sistema partidario (LEIRAS, 2009). Cuando se rearmaron las líneas internas del PJ, aparecieron neo-caudillos con proyección nacional: Kirchner, Rodríguez Saá y Menem. Con la no realización de internas del PJ, se imprimió aún más radicalismo al federalismo partidario. Esto se reflejó con la territorialización del voto, que apareció en las elecciones presidenciales de abril de 2003. Hubo que definir quiénes llegaban a segunda vuelta, y quién "vendería" sus reductos electorales ${ }^{6}$ a cambio de recursos financieros y administrativos. Rodríguez Saá, de SLU y con buena performance en Cuyo, quedo afuera del ballotage, donde se enfrentarían Kirchner -victorioso en la Patagonia y en BUE- y Menem -que había vencido en todo el Noroeste, con LRJ como mayor "corral electoral”. Este patrón se repitió en las elecciones generales de 2007, donde el FpV conquistó, además de la mayoría de los gobiernos provinciales y gran cantidad de legisladores, la Presidencia, con Fernández de Kirchner-Cobos. Esta fórmula arrasó en la periferia de Buenos Aires y en las "Provincias Periféricas", pero no obtuvo el primer lugar en la preferencia de los electores en los principales núcleos urbanos del país (Buenos Aires, Córdoba, Rosario, La Plata, etc.). Así, en los últimos años, es evidente la desnacionalización y descentralización del sistema partidario (LEIRAS, 2009), con un perfil extremadamente regionalizado, en un escenario político caracterizado por la robustez de las Provincias con papeles políticos de primera línea.

Entonces, los grandes partidos argentinos modificaron su potencial electoral, con una distinción en las preferencias según la localización geográfica y mayores grados de volatilidad electoral. La fragmentación de los partidos se expresa tanto en la no realización de internas como en la cantidad de listas que aparecen en cada elección. Por lo tanto, no se concuerda con Cardozo (2008), quien coloca a los partidos argentinos como máquinas nacionales omnipotentes que, a través de la disciplina partidaria, subyugan a los legisladores, quienes representarían al partido y no ya al distrito que los eligió. Destaca Benton (2003) que, antes de hablar de "partidos nacionales" en

\footnotetext{
${ }^{6}$ En SLU, el partido de Rodríguez Saá obtuvo el 87,39\% de los votos. El FpV de Kirchner logró 78,69\% de los votos en SCR. Por su parte, el 81,93\% de los votos en LRJ fueron para la fórmula Menem-Romero. 7 Son consideradas como "Provincias Periféricas" MZA, TUC, ERI, SAL, CHA, MIS, COR, SGO, SJU, JUJ, RNO, NEU, FOR, CHU, SLU, CAT, LAP, LRJ, SCR y TDF.
} 
Argentina, sería correcto describirlos como coaliciones de organizaciones partidarias de las Provincias.

\section{2 ¿PARTIDOS REGIONALES O NACIONALES EN BRASIL?}

Los partidos brasileños se caracterizan por su desempeño regional, consideran diversos autores (STEPAN, 1999; CARDARELLO, 2009). Los partidos en Brasil, desde la proclamación de la República (1888), permanecieron regionalizados. La Revolução de 1930 y el Régimen Militar (1964/85) no lograron que un nuevo sistema de partidos emergiera nacionalmente, y menos aún esto sucedería en democracia. Como las organizaciones estaduales cuentan con amplia autonomía al interior de los partidos, estos no actuarían nacionalmente, sino siguiendo un patrón regionalizado, con reductos electorales en ciertos Estados. Así, la victoria de los partidos nacionales se daría en regiones específicas. Pero, un conjunto de leyes aplicado en los últimos años habría cambiado esta realidad, por la homogeneización de las reglas electorales en todo Brasil, las cuales modificaron el juego político, nacionalizando las elecciones.

Se puede pensar aquí en las elecciones directas para la Presidencia del actual período democrático, tomando sólo el primer turno electoral. Collor de Mello (Partido da Reconstrução Nacional), en 1989, fue el candidato más votado en 23 de las 27 UF, con presencia en todas las regiones. En 1994, Cardoso (PSDB) hizo lo propio, perdiendo sólo en 2 distritos. En 1998, se dio una situación similar con la reelección de Cardoso. En 2002, Lula da Silva (PT) fue el candidato más votado en casi todos los distritos. Así, ninguna elección presidencial entre 1989 y 2002 reconoce un patrón partidario, algo que sí sucedió en 2006, cuando Lula fue reelecto. Aquí, la distinción territorial se vio nítidamente: votación en bloque para Gerardo Alckmin (PSDB) en el Sur y el CentroOeste, y lo mismo para Lula en el Nordeste, el Norte y el Sudeste. En el primer turno de 2010, el mapa brasileño repite prácticamente los mismos parámetros: a grandes rasgos, Dilma Rousseff lideró la disputa en el Nordeste, el Norte y el Centro-Oeste ${ }^{8}$, y José Serra fue el más votado en el Sur y en algunos Estados del Sudeste.

Se analiza ahora si el patrón regionalizado de votación se repite en los pleitos proporcionales. Roma y Braga (2002) rechazan esa tesis, considerando que los grandes partidos brasileños trabajan como colectivos ideológicos orientados electoralmente. Así, Brasil habría asistido a la nacionalización de sus partidos, a través de un triple proceso: la disminución de la dispersión electoral en los Estados; el avance de la representación electoral de los grandes partidos, que logran mayoría de votos en casi todos los Estados; y comportamientos estratégicos por parte de los líderes partidarios

\footnotetext{
8 Óptima fue la performance obtenida por Marina Silva (PV) en el Distrito Federal, donde conquistó el
} $41,96 \%$ de los votos. 
cuando hacen alianzas electorales. Solamente sería posible ver la regionalización de los grandes partidos en los períodos inmediatamente posteriores a su fundación, cuando aún están concentrados en algunos Estados. Entre los partidos de mayor despliegue territorial, se sitúan el PMDB, PSDB, PT, DEM, Partido Progressista, PTB y PDT, que, en conjunto, alcanzaron el $78 \%$ de las bancas en 2002, el 73\% en 2006 y el 68\% en 2010, con excelentes desempeños territoriales, no limitados regionalmente. Así, antes de confirmarse la teoría de la regionalización partidaria, sería más sólida la visión de Roma y Braga: los grandes partidos deciden el juego político, con buenas performances en todas las regiones de Brasil; y los otros partidos, en la medida en que logran resultados favorables, logran expandir sus áreas de actuación, nacionalizándose, y colocando representantes de todas las regiones en la Câmara dos Deputados.

\section{SUB Y SOBRE-REPRESENTACIÓN DISTRITAL (SRD) A NIVEL FEDERAL}

El concepto "sobre-representación distrital" (SRD, establecido por Reynoso, 2001) se refiere al fenómeno conocido por el término inglés "malapportionment", acuñado por Burt Monroe. Este vocablo hace referencia a todas las diferencias entre el porcentual total de electores y el porcentual de bancas que se atribuyen en un mismo distrito, o sea sobre- y sub-representación.

Nuestros países siguen la regla de todos los federalismos: cuentan con un Legislativo bicameral9 como una de las características medulares. A diferencia de los países unicamerales, aquí existe una segunda cámara, ideada siguiendo un criterio no poblacional sino territorial, que no discrimina entre unidades pequeñas o grandes, sino que tutela a todas estas de modo a hacerlas participar efectivamente en el Legislativo federal. Entonces, si la cámara territorial se basa en un criterio federal, será poco o nada proporcional: en nuestros casos, las unidades intermedias poseen tres representantes al Senado Federal. Para medir la SRD, se tienen en cuenta las fórmulas de Reynoso (2001; 2004) que alteran la clásica fórmula de Loosemore y Handy. El índice que Reynoso presenta es el siguiente: $\mathbf{S R D}=\mathbf{1} \mathbf{2} \Sigma \mid \mathbf{\%}$ - \%M|, donde $P$ es el total de electores y $M$ representa la cantidad de representantes.

Debido a las disparidades demográficas, el grado de desproporcionalidad del Senado Federal brasileño y del Senado de la Nación argentino está entre los mayores del mundo. Tomando la UF con el mayor contingente electoral (SP, y BUE, respectivamente) y el menor de cada país (RR en Brasil, y TDF en Argentina), la

9 Cabe aclarar que existen países de organización unitaria que, por distintas circunstancias, cuentan con una segunda cámara. 
diferencia entre la cantidad de electores es de 120 y de 109,9 veces, en debido orden. Conforme a investigaciones elaboradas por Reynoso (2004), Argentina (49,73\% en 1997) y Brasil (41,74\% en 1998) estaban entre los países con mayor índice de SRD del mundo, siendo que, entre países federales, ocupaban el primero y segundo lugar. Estos porcentuales parecen atenuarse en los últimos 10 años: Brasil tiene una sobrerepresentación distrital en el Senado de 40,14\% en 2006, en cuanto que el país platino bajó el índice para 46,96\% en 2009. Pero, según Stepan (1999), es esta desproporción una de las variables que operan sistemáticamente en todos los federalismos: toda cámara alta en sistemas federales, irremediablemente, será desproporcional. También Samuels y Snyder (2001) van en esa dirección cuando afirman que los países grandes, debido a que poseen enormes extensiones territoriales escasamente pobladas, tienden naturalmente a sobre-representar sus regiones menos pobladas. Por lo tanto, no se profundiza el análisis de este fenómeno al caso de los Senados. Porque el Senado es el ámbito donde se respeta el principio de la soberanía de los Estados miembros, dando a cada uno de ellos la misma potencia. Entonces, ¿dónde está el problema? La cuestión se torna relevante al analizar las cámaras bajas. Estas cámaras, en sistemas federales, en general, se basan en el principio poblacional. La idea es que cada Estado está representado en el Legislativo federal con relación a su peso demográfico, siguiendo el criterio de la proporcionalidad. En la práctica, dejando de lado aquellos sistemas electorales donde la elección de diputados se hace tomando el país como distrito único, una perfecta proporcionalidad es imposible.

\subsection{LA SRD DESDE EL RETORNO A LA DEMOCRACIA}

Antes de las elecciones generales de 1983, los integrantes del "Proceso de Reorganización Nacional" promulgaron los decretos-ley $\mathrm{N}^{\circ} 22.838 / 83$ y $22.847 / 83$. A través de estos, fueron creadas nuevas reglas electorales que elevaron de tres para cinco el número mínimo de representantes por Provincia, independiendo el factor poblacional-electoral. En 1991, cuando Tierra del Fuego deja de ser Territorio Nacional para tornarse Provincia, también tuvo el derecho de enviar sus cinco representantes. 
Tabla 5. Arg. Electores, Magn. y Razón de votos ${ }^{10}$

\begin{tabular}{|c|c|c|c|c|c|}
\hline UF & $\mathbf{Q E}$ & $\mathrm{QE}$ & $\mathbf{M}$ & $\% \mathrm{M}$ & $\mathrm{R}$ \\
\hline BUE & 10.335 .398 & 37,19 & 70 & 27,24 & 147.649 \\
\hline & & & & & 100.33 \\
\hline CABA & 2.508.353 & 9,03 & 25 & 9,73 & 4 \\
\hline CBA & 2.439.557 & 8,78 & 19 & 7,39 & $\begin{array}{r}128.39 \\
8\end{array}$ \\
\hline SFE & 2.375 .271 & 8,55 & 18 & 7,00 & 131.960 \\
\hline MZA & 1.181 .848 & 4,25 & 10 & 3,89 & 118.185 \\
\hline TUC & 980.230 & 3,53 & 9 & 3,50 & 108.914 \\
\hline ERI & 889.190 & 3,20 & 9 & 3,50 & 98.799 \\
\hline SAL & $773 \cdot 314$ & 2,78 & 7 & 2,72 & 110.473 \\
\hline & & & & & 102.64 \\
\hline CHA & 718.502 & 2,59 & 7 & 2,72 & $\mathbf{3}$ \\
\hline MIS & 691.198 & 2,49 & 7 & 2,72 & 98.743 \\
\hline $\mathrm{COR}$ & 671.152 & 2,42 & 7 & 2,72 & 95.879 \\
\hline SGO & 576.913 & 2,08 & 7 & 2,72 & 82.416 \\
\hline SJU & 450.774 & 1,62 & 6 & 2,33 & 75.129 \\
\hline JUJ & 424.182 & 1,53 & 6 & 2,33 & 70.697 \\
\hline RNO & $415 \cdot 748$ & 1,50 & 5 & 1,95 & 83.150 \\
\hline NEU & 386.848 & 1,39 & 5 & 1,95 & $77 \cdot 370$ \\
\hline FOR & 348.695 & 1,25 & 5 & 1,95 & 69.739 \\
\hline $\mathrm{CHU}$ & 338.548 & 1,22 & 5 & 1,95 & 67.710 \\
\hline SLU & 297.628 & 1,07 & 5 & 1,95 & 59.526 \\
\hline CAT & 247.262 & 0,89 & 5 & 1,95 & 49.452 \\
\hline LAP & 241.127 & 0,87 & 5 & 1,95 & 48.225 \\
\hline LRJ & 218.226 & 0,79 & 5 & 1,95 & 43.645 \\
\hline SCR & 185.233 & 0,67 & 5 & 1,95 & 37.047 \\
\hline TDF & 94.076 & 0,34 & 5 & 1,95 & 18.815 \\
\hline ARG & 27.789.273 & 100,0 & $\mathbf{2 5 7}$ & 100,0 & 108.129 \\
\hline
\end{tabular}

Nota: Los datos se refieren a junio de 2009, últimas cifras disponibles antes del pleito legislativo de 2009. Fuente: Elaboración propia en base a Dirección Nacional Electoral (2009).
Tabla 6. Brasil. Electores, Magn. y Razón de votos

\begin{tabular}{lccccc} 
UF & QE & $\% Q E$ & M & $\% M$ & R \\
\hline \hline SP & $\mathbf{2 8 . 0 3 7 . 7 3 4}$ & 22,28 & $\mathbf{7 0}$ & 13,65 & $\mathbf{4 0 0 . 5 3 9}$ \\
\hline MG & $\mathbf{1 3 . 6 7 9 . 7 3 8}$ & 10,87 & $\mathbf{5 3}$ & 10,33 & $\mathbf{2 5 8 . 1 0 8}$ \\
\hline RJ & $\mathbf{1 0 . 8 9 1 . 2 9 3}$ & 8,66 & $\mathbf{4 6}$ & 8,97 & $\mathbf{2 3 6 . 7 6 7}$ \\
\hline BA & $\mathbf{9 . 1 0 9 . 3 5 3}$ & 7,24 & $\mathbf{3 9}$ & 7,60 & $\mathbf{2 3 3 . 5 7 3}$ \\
\hline RS & $\mathbf{7 . 7 5 0 . 5 8 3}$ & 6,16 & $\mathbf{3 1}$ & 6,04 & $\mathbf{2 5 0 . 0 1 9}$ \\
\hline PR & $\mathbf{7 . 1 2 1 . 2 5 7}$ & 5,66 & $\mathbf{3 0}$ & 5,85 & $\mathbf{2 3 7 . 3 7 5}$ \\
\hline PE & $\mathbf{5 . 8 3 4 . 5 1 2}$ & 4,64 & $\mathbf{2 5}$ & 4,87 & $\mathbf{2 3 3 . 3 8 0}$ \\
\hline CE & $\mathbf{5 . 3 6 1 . 5 8 1}$ & 4,26 & $\mathbf{2 2}$ & 4,29 & $\mathbf{2 4 3 . 7 0 8}$ \\
\hline
\end{tabular}

\begin{tabular}{l|rrrrr}
\hline SC & $\mathbf{4 . 1 6 8 . 4 9 5}$ & 3,31 & $\mathbf{1 6}$ & 3,12 & $\mathbf{2 6 0 . 5 3 1}$ \\
\hline PA & $\mathbf{4 . 1 5 7 . 7 3 5}$ & 3,30 & $\mathbf{1 7}$ & 3,31 & $\mathbf{2 4 4 . 5 7 3}$ \\
\hline MA & $\mathbf{3 . 9 2 0 . 6 0 8}$ & 3,12 & $\mathbf{1 8}$ & 3,51 & $\mathbf{2 1 7 . 8 1 2}$ \\
\hline GO & $\mathbf{3 . 7 3 4 . 1 8 5}$ & 2,97 & $\mathbf{1 7}$ & 3,31 & $\mathbf{2 1 9 . 6 5 8}$ \\
\hline PB & $\mathbf{2 . 5 7 3 . 7 6 6}$ & 2,05 & $\mathbf{1 2}$ & 2,34 & $\mathbf{2 1 4 . 4 8 1}$ \\
\hline ES & $\mathbf{2 . 3 3 6 . 1 3 3}$ & 1,86 & $\mathbf{1 0}$ & 1,95 & $\mathbf{2 3 3 . 6 1 3}$ \\
\hline RN & $\mathbf{2 . 1 0 1 . 1 4 4}$ & 1,67 & $\mathbf{8}$ & 1,56 & $\mathbf{2 6 2 . 6 4 3}$ \\
\hline PI & $\mathbf{2 . 0 7 3 . 5 0 4}$ & 1,65 & $\mathbf{1 0}$ & 1,95 & $\mathbf{2 0 7 . 3 5 0}$ \\
\hline MT & $\mathbf{1 . 9 4 0 . 2 7 0}$ & 1,54 & $\mathbf{8}$ & 1,56 & $\mathbf{2 4 2 . 5 3 4}$ \\
\hline AL & $\mathbf{1 . 8 5 9 . 4 8 7}$ & 1,48 & $\mathbf{9}$ & 1,75 & $\mathbf{2 0 6 . 6 1 0}$ \\
\hline AM & $\mathbf{1 . 7 8 1 . 3 1 6}$ & 1,42 & $\mathbf{8}$ & 1,56 & $\mathbf{2 2 2 . 6 6 5}$ \\
\hline DF & $\mathbf{1 . 6 5 5 . 0 5 0}$ & 1,32 & $\mathbf{8}$ & 1,56 & $\mathbf{2 0 6 . 8 8 1}$ \\
\hline MS & $\mathbf{1 . 5 6 1 . 1 8 1}$ & 1,24 & $\mathbf{8}$ & 1,56 & $\mathbf{1 9 5 . 1 4 8}$ \\
\hline SE & $\mathbf{1 . 2 9 9 . 7 8 5}$ & 1,03 & $\mathbf{8}$ & 1,56 & $\mathbf{1 6 2 . 4 7 3}$ \\
\hline RO & $\mathbf{9 8 8 . 6 3 1}$ & 0,79 & $\mathbf{8}$ & 1,56 & $\mathbf{1 2 3 . 5 7 9}$ \\
\hline TO & $\mathbf{8 8 2 . 7 2 8}$ & 0,70 & $\mathbf{8}$ & 1,56 & $\mathbf{1 1 0 . 3 4 1}$ \\
\hline AC & $\mathbf{4 1 2 . 8 4 0}$ & 0,33 & $\mathbf{8}$ & 1,56 & $\mathbf{5 1 . 6 0 5}$ \\
\hline AP & $\mathbf{3 6 0 . 6 1 4}$ & 0,29 & $\mathbf{8}$ & 1,56 & $\mathbf{4 5 . 0 7 7}$ \\
\hline RR & $\mathbf{2 3 3 . 5 9 6}$ & 0,19 & $\mathbf{8}$ & 1,56 & $\mathbf{2 9 . 2 0 0}$ \\
\hline BRA & $\mathbf{1 2 5 . 8 2 7 . 1 1 9}$ & 100,0 & $\mathbf{5 1 3}$ & 100,0 & $\mathbf{2 4 5 . 2 7 7}$ \\
\hline
\end{tabular}

Nota: Los datos se refieren a junio de 2006, últimas cifras disponibles antes del pleito legislativo de octubre de ese año. Fuente: Elaboración propia en base a Tribunal Superior Eleitoral (2009).

10 "R" es la razón entre la cantidad de electores (QE) y la magnitud del distrito (M). Se aclara que en ambos casos, fueron excluidos los electores del "Exterior", o sea aquellos que viven fuera del respectivo país. 
El caso brasileño no es muy diferente. Poco tiempo antes de las elecciones de 1982, se implantó una serie de medidas electorales que, entre otras cosas, elevaron el "techo" a 60 diputados, al mismo tiempo en que fue aumentada para 8 la cantidad mínima de representantes por Estado, "piso" que está vigente hasta hoy. Finalmente, uno de los cambios que la CF88 trajo fue que el "techo" pasó a ser de 70 diputados. Nicolau (1997) afirma que existen dos formas de violar el criterio proporcional: por medio de la falta de revisión periódica de los patrones demográficos en las UF, y a través de las reglas establecidas para la conquista de bancas. En Argentina y Brasil, las dos formas están presentes, mediante el establecimiento de "pisos" (y de "techos", algo exclusivo del caso brasileño), y a través de la manutención del número de bancas, aunque pasen elecciones, censos y actualizaciones demográficas. A continuación, se analiza el fenómeno de la sobre-representación distrital en las cámaras bajas de Argentina y Brasil. Primeramente, aparece la Tabla $\mathrm{N}^{0} 7$, que muestra el fenómeno de la SRD en la Câmara dos Deputados brasileña, con datos de 2006.

Tabla 7. Brasil. SRD en la Câmara (2006), y n. de bancas proporcional a la pobl. de los Estados

\begin{tabular}{|c|c|c|c|c|c|c|}
\hline Unidad Federativa & $\% Q E$ & $\mathbf{M}$ & \%Magn. & SRD Total & Dif. & Mprop \\
\hline São Paulo & 22,28 & 70 & 13,65 & $-8,63$ & 22,28 & 114 \\
\hline Minas Gerais & 10,87 & 53 & 10,33 & $-0,54$ & 10,87 & 56 \\
\hline Rio de Janeiro & 8,66 & 46 & 8,97 & $\mathbf{0 , 3 1}$ & 8,66 & 44 \\
\hline Bahia & 7,24 & 39 & 7,60 & 0,36 & 7,24 & $\mathbf{3 7}$ \\
\hline Rio Grande do Sul & 6,16 & 31 & 6,04 & $-0,12$ & 6,16 & 32 \\
\hline Paraná & 5,66 & 30 & 5,85 & $\mathbf{0 , 1 9}$ & 5,66 & 29 \\
\hline Pernambuco & 4,64 & 25 & 4,87 & $\mathbf{0 , 2 3}$ & 4,64 & 24 \\
\hline Ceará & 4,26 & 22 & 4,29 & $\mathbf{0 , 0 3}$ & 4,26 & 22 \\
\hline Santa Catarina & $\mathbf{3 , 3 1}$ & 16 & 3,12 & $-0,19$ & 3,31 & 17 \\
\hline Pará & $\mathbf{3 , 3 0}$ & 17 & 3,31 & $\mathbf{0 , 0 1}$ & 3,30 & 17 \\
\hline Maranhão & 3,12 & 18 & 3,51 & $\mathbf{0 , 3 9}$ & 3,12 & 16 \\
\hline Goiás & $\mathbf{2 , 9 7}$ & 17 & 3,31 & $\mathbf{0 , 3 4}$ & 2,97 & 15 \\
\hline Paraíba & $\mathbf{2 , 0 5}$ & 12 & 2,34 & $\mathbf{0 , 2 9}$ & 2,05 & $\mathbf{1 1}$ \\
\hline Espírito Santo & $\mathbf{1 , 8 6}$ & 10 & 1,95 & $\mathbf{0 , 0 9}$ & 1,86 & 10 \\
\hline Rio Grande do Norte & $\mathbf{1 , 6 7}$ & 8 & 1,56 & $-\mathbf{0 , 1 1}$ & 1,67 & 9 \\
\hline Piauí & $\mathbf{1 , 6 5}$ & 10 & 1,95 & $\mathbf{0 , 3 0}$ & 1,65 & 8 \\
\hline Mato Grosso & 1,54 & 8 & 1,56 & $\mathbf{0 , 0 2}$ & 1,54 & 8 \\
\hline Alagoas & 1,48 & 9 & 1,75 & $\mathbf{0 , 2 7}$ & 1,48 & 8 \\
\hline Amazonas & 1,42 & 8 & 1,56 & $\mathbf{0 , 1 4}$ & 1,42 & 7 \\
\hline
\end{tabular}




\begin{tabular}{lcccccc}
\hline Distrito Federal & $\mathbf{1 , 3 2}$ & $\mathbf{8}$ & 1,56 & $\mathbf{0 , 2 4}$ & 1,32 & 7 \\
\hline Mato Grosso do Sul & $\mathbf{1 , 2 4}$ & $\mathbf{8}$ & 1,56 & $\mathbf{0 , 3 2}$ & 1,24 & $\mathbf{6}$ \\
\hline Sergipe & $\mathbf{1 , 0 3}$ & $\mathbf{8}$ & 1,56 & $\mathbf{0 , 5 3}$ & 1,03 & $\mathbf{5}$ \\
\hline Rondônia & $\mathbf{0 , 7 9}$ & $\mathbf{8}$ & 1,56 & $\mathbf{0 , 7 7}$ & 0,79 & $\mathbf{4}$ \\
\hline Tocantins & $\mathbf{0 , 7 0}$ & $\mathbf{8}$ & 1,56 & $\mathbf{0 , 8 6}$ & 0,70 & $\mathbf{4}$ \\
\hline Acre & $\mathbf{0 , 3 3}$ & $\mathbf{8}$ & 1,56 & $\mathbf{1 , 2 3}$ & 0,33 & $\mathbf{2}$ \\
\hline Amapá & $\mathbf{0 , 2 9}$ & $\mathbf{8}$ & 1,56 & $\mathbf{1 , 2 7}$ & \multirow{2}{*}{0,29} & $\mathbf{1}$ \\
\hline Roraima & $\mathbf{0 , 1 9}$ & $\mathbf{8}$ & 1,56 & $\mathbf{1 , 3 7}$ & 0,19 & $\mathbf{1}$ \\
\hline Total Brasil & $\mathbf{1 0 0 , 0 0}$ & $\mathbf{5 1 3}$ & 100, oo & $\mathbf{9 , 5 8}$ & 100,00 & $\mathbf{5 1 3}$ \\
\hline Fuente: Elaboración propia en base a Tribunal Superior Eleitoral (2009). &
\end{tabular}

Es evidente la sub-representación de los Estados de las Regiones Sur y Sudeste. SP y MG, los mayores colegios electorales, son también los más perjudicados por la SRD. Otras unidades históricamente sub-representadas son RS y SC. Exceptuando RN y MT, todas las subunidades federales que tienen el "piso" mínimo de 8 diputados están altamente sobre-representadas. Siguiendo el principio poblacional, les corresponderían menos diputados de los que efectivamente poseen. De estos Estados, seis son de la Región Norte, otros dos del Nordeste, y el restante es del CentroOeste. Un 9,58\% de SRD representa un total de 50 bancas, que corresponderían a SP (44); MG (3); RS, SC y RN (una cada uno). Esas bancas van, mayoritariamente, para los Estados menos poblados del Norte, Centro-Oeste y Nordeste, con casos extremos como los de RR y AM, que contando con ocho diputados, "merecerían" sólo una cada uno. Tampoco se debe olvidar la parte de arriba de la Tabla $\mathrm{N}^{\circ} 8$, donde se evidencia que RJ, BA y MA, por ejemplo, también son Estados sobre-representados.

Se pasa ahora al sistema federal argentino. Aquí el fenómeno se repite, aunque los valores puedan variar. En Argentina, la Cámara desde diciembre de 2009, cuenta con miembros que asumieron en 2007 (cuyo mandato se extiende hasta 2011) y otros que, tomando pose hace poco, trabajarán hasta 2013. Así, la Tabla $N^{\circ} 8$ está elaborada con base en datos de 2007 y de 2009.

\section{Tabla 8. Argentina. SRD en la Cámara (2007 y 2009), y n. de bancas proporcional a la pobl. de las Provincias}

\begin{tabular}{|c|c|c|c|c|c|c|c|c|c|c|}
\hline $\begin{array}{l}\text { Unidad } \\
\text { Federativa }\end{array}$ & $\begin{array}{c}\% Q E \\
\text { o7 }\end{array}$ & $\begin{array}{l}\mathbf{M} \\
\mathbf{0 7}\end{array}$ & $\begin{array}{c}\% \mathrm{M} \\
\mathrm{O}\end{array}$ & $\begin{array}{c}S R D \\
07\end{array}$ & $\begin{array}{c}\% Q E \\
\text { o9 }\end{array}$ & $\begin{array}{l}\text { M } \\
\mathbf{0 9}\end{array}$ & $\begin{array}{c}\% \mathrm{M} \\
\mathrm{O9}\end{array}$ & SRD O9 & Dif. & $\begin{array}{c}\text { Mpro } \\
\text { p }\end{array}$ \\
\hline Buenos Aires & $\mathbf{3 7 , 0 5}$ & 35 & 26,92 & $-10,13$ & 37,19 & 35 & 27,56 & $-9,63$ & 37,19 & 96 \\
\hline $\begin{array}{l}\text { C. A. de Buenos } \\
\text { Aires }\end{array}$ & $\mathbf{9 , 5 2}$ & 12 & 9,23 & $-0,29$ & $\mathbf{9 , 0 3}$ & 13 & 10,24 & $\mathbf{1 , 2 1}$ & 9,03 & $\mathbf{2 3}$ \\
\hline Córdoba & 8,73 & 9 & 6,92 & $-1,81$ & 8,78 & 9 & 7,09 & $-1,69$ & 8,78 & $\mathbf{2 3}$ \\
\hline
\end{tabular}




\begin{tabular}{|c|c|c|c|c|c|c|c|c|c|c|}
\hline Santa Fe & 8,59 & 10 & 7,69 & $-\mathbf{0 , 9 0}$ & 8,55 & 9 & 7,09 & $-1,46$ & 8,55 & 22 \\
\hline Mendoza & 4,21 & 5 & 3,85 & $-0,36$ & 4,25 & 5 & 3,94 & $-\mathbf{0 , 3 1}$ & 4,25 & 11 \\
\hline Tucumán & $\mathbf{3 , 5 0}$ & 5 & 3,85 & $\mathbf{0 , 3 5}$ & $\mathbf{3 , 5 3}$ & 4 & 3,15 & $-\mathbf{0 , 3 8}$ & 3,53 & 9 \\
\hline Entre Ríos & $\mathbf{3 , 2 1}$ & 4 & 3,08 & $-\mathbf{0 , 1 3}$ & 3,20 & 5 & 3,94 & 0,74 & 3,20 & 8 \\
\hline Salta & $\mathbf{2 , 7 7}$ & 4 & 3,08 & $\mathbf{0 , 3 1}$ & 2,78 & 3 & 2,36 & $-0,42$ & 2,78 & 7 \\
\hline Chaco & 2,60 & 3 & 2,31 & $-0,29$ & $\mathbf{2 , 5 9}$ & 4 & 3,15 & 0,56 & 2,59 & 7 \\
\hline Misiones & $\mathbf{2 , 4 5}$ & 4 & 3,08 & $\mathbf{0 , 6 3}$ & 2,49 & 3 & 2,36 & $-0,13$ & 2,49 & 6 \\
\hline Corrientes & 2,43 & 4 & 3,08 & $\mathbf{0 , 6 5}$ & 2,42 & 3 & 2,36 & $-0,06$ & 2,42 & 6 \\
\hline Santiago del Estero & 2,06 & 4 & 3,08 & $\mathbf{1 , 0 2}$ & 2,08 & 3 & 2,36 & $\mathbf{0 , 2 8}$ & 2,08 & 5 \\
\hline San Juan & 1,62 & 3 & 2,31 & $\mathbf{0 , 6 9}$ & 1,62 & 3 & 2,36 & 0,74 & 1,62 & 4 \\
\hline Jujuy & $\mathbf{1 , 5 2}$ & 3 & 2,31 & 0,79 & $\mathbf{1 , 5 3}$ & 3 & 2,36 & $\mathbf{0 , 8 3}$ & 1,53 & 4 \\
\hline Río Negro & 1,45 & 3 & 2,31 & $\mathbf{0 , 8 6}$ & $\mathbf{1 , 5 0}$ & 2 & 1,57 & $\mathbf{0 , 0 7}$ & 1,50 & 4 \\
\hline Neuquén & 1,35 & 2 & 1,54 & $\mathbf{0 , 1 9}$ & 1,39 & 3 & 2,36 & $\mathbf{0 , 9 7}$ & 1,39 & 4 \\
\hline Formosa & 1,23 & 3 & 2,31 & 1,08 & 1,25 & 2 & 1,57 & $\mathbf{0 , 3 2}$ & 1,25 & 3 \\
\hline Chubut & $\mathbf{1 , 1 9}$ & 3 & 2,31 & $\mathbf{1 , 1 2}$ & 1,22 & 2 & 1,57 & $\mathbf{0 , 3 5}$ & 1,22 & 3 \\
\hline San Luis & $\mathbf{1 , 0 7}$ & 2 & 1,54 & $\mathbf{0 , 4 7}$ & $\mathbf{1 , 0 7}$ & 3 & 2,36 & 1,29 & 1,07 & 3 \\
\hline Catamarca & $\mathbf{0 , 8 9}$ & 2 & 1,54 & 0,65 & $\mathbf{0 , 8 9}$ & 3 & 2,36 & $\mathbf{1 , 4 7}$ & 0,89 & 2 \\
\hline La Pampa & $\mathbf{o , 8} 7$ & 2 & 1,54 & $\mathbf{0 , 6 7}$ & $\mathbf{0 , 8 7}$ & 3 & 2,36 & 1,49 & 0,87 & 2 \\
\hline La Rioja & 0,78 & 3 & 2,31 & $\mathbf{1 , 5 3}$ & 0,79 & 2 & 1,57 & 0,78 & 0,79 & 2 \\
\hline Santa Cruz & $\mathbf{0 , 5 9}$ & 2 & 1,54 & $\mathbf{0 , 9 5}$ & 0,67 & 3 & 2,36 & 1,69 & 0,67 & 2 \\
\hline Tierra del Fuego & $\mathbf{0 , 3 3}$ & 3 & 2,31 & 1,98 & $\mathbf{0 , 3 4}$ & 2 & 1,57 & 1,23 & 0,34 & $\mathbf{1}$ \\
\hline Total Argentina & 100,0 & 130 & 100,0 & 13,91 & 100,0 & 127 & 100,0 & 14,07 & 100,00 & $\mathbf{2 5 7}$ \\
\hline
\end{tabular}

Fuente: Elaboración propia en base a Dirección Nacional Electoral (2009).

En primer lugar, se observa que los índices de SRD total (13,91\% para 2007, y 14,07\% para 2009) para la cámara poblacional son más altos que en Brasil, hecho que también sucede, como fue advertido, en la cámara alta. Pero, siguiendo a Reynoso (2004), se ve que en la última década los índices de SRD son menores hoy que durante los 90: en 1993, eran del 15,17\%, y en 1995 del 16,28\%. Independientemente de la magnitud, existen Provincias insistentemente sub-representadas. BUE (-26) es la más afectada, seguida por CBA y SFE (-4) y MZA (-1). Las unidades de menor peso electoral están altamente sobre-representadas, percibiéndose un traslado de 35 bancas desde las mayores jurisdicciones a las menores, localizadas en la Patagonia, Cuyo y el Norte Grande.

Así, el conjunto de características del sistema político (cantidad de distritos; magnitud efectiva; fórmula electoral; reglas de nominación de candidatos y tipo de lista) genera, en nuestros países, el fenómeno de la SRD -o "sesgo mayoritario" en 
términos de Calvo (2001). Se asiste a un altísimo grado de sobre-representación, elemento que aparece naturalmente en las cámaras altas, pero que se repite en las cámaras proporcionales, intencionalmente. Siguiendo a Reynoso (2001), este fenómeno mantiene una distancia entre el poder económico y la representación política. Permitiendo que los distritos menores tengan más bancas de las que les “corresponderían", se les da a estos la posibilidad de negociar recursos económicos y obras públicas del Estado federal a cambio de apoyos en las Cámaras. Y, en relación al principio de la igualdad del voto, se genera el hecho de que una mayoría de electores puede quedar como minoría en el Legislativo y, al contrario, una minoría electoral se puede convertir en una mayoría legislativa muy poderosa (REYNOSO, 2004, 89).

\section{2 ¿CÓMO LA SRD AFECTA A LOS PARTIDOS POLÍTICOS?}

Nohlen (1994) entiende que la desigualdad del voto en la Cámara se constituye en una desventaja para los partidos de perfil urbano y progresista, porque premia a las UF menos pobladas, dando ventaja para aquellos agrupamientos más conservadores. Este autor cree que es en los grandes centros urbanos donde la complejidad social se refleja en el sistema de partidos, y las ideologías progresistas poseen un peso mayor. $\mathrm{Si}$ los votos de algunos electores valen más que los de otros, también existen partidos cuyos votos valen más, cuando sus electores no se distribuyen uniformemente en el territorio. La ventaja de estos partidos en la relación votos-bancas se llama "sesgo partidario" (CALVO et al., 2001, 61). Este es claro en Argentina, donde PJ y UCR tienen amplio despliegue territorial y consiguen bancas gracias a buenas performances en el interior, mientras que los partidos de base urbana (como el FG -luego, FREPASO, el AR, etc.) son perjudicados. También los partidos provinciales son beneficiados por la SRD en sus distritos (REYNOSO, 2004, 84). La Tabla $\mathrm{N}^{\circ} 9$ muestra datos de las elecciones de 1993 y 1997.

Tabla 9. Argentina. SRD en la Câmara por partido (1993 y 1997)

Dif. \%V-

Dif. \%V-

\begin{tabular}{|c|c|c|c|c|c|c|c|}
\hline Partido & \%V 93 & $\% C 93$ & $\% \mathrm{C}$ & Partido & \%V 97 & $\% C 97$ & $\% \mathrm{C}$ \\
\hline PJ & 42,5 & 50,3 & 7,8 & PJ & 36,3 & 39,4 & 3,1 \\
\hline UCR & 30,2 & 32,3 & 2,1 & ALIANZA & 36,6 & 37,0 & 0,4 \\
\hline MODIN & 5,8 & 3,2 & $-2,6$ & UCR & 7,0 & 9,3 & 2,3 \\
\hline FREPASO & 3,5 & 2,4 & $-1,1$ & FREPASO & $\mathbf{2 , 0}$ & 2,4 & 0,4 \\
\hline UceDé & 2,6 & $o, 8$ & $-1,8$ & $\mathrm{AR}$ & 3,8 & 2,4 & $-1,4$ \\
\hline US & 1,6 & 1,6 & 0,0 & FR-TUC & 1,4 & 1,6 & 0,2 \\
\hline
\end{tabular}


Tabla 9. Argentina. SRD en la Câmara por partido (1993 y 1997)

Dif. \%V-

Dif. \%V-

\begin{tabular}{lccc} 
Partido & $\% \mathrm{~V} 93$ & $\% \mathrm{C} 93$ & $\% \mathrm{C}$ \\
\hline FR-TUC & 1,4 & 0,8 & $\mathbf{- 0 , 6}$ \\
PDP & 1,3 & 0,8 & $\mathbf{- o , 5}$ \\
\hline PAL-COR & 1,1 & 1,6 & 0,5 \\
\hline FdelaV & 0,9 & 0,8 & $\mathbf{- o , 1}$ \\
\hline ACH-CHA & 0,8 & 0,8 & 0,0 \\
\hline PR-SAL & 0,7 & 0,8 & 0,1 \\
\hline PD-MZA & 0,7 & 0,8 & 0,1 \\
\hline MPN-NEU & 0,3 & 0,8 & 0,5 \\
\hline MOPOJ-JUJ & 0,3 & 0,8 & 0,5 \\
\hline MOPOF-TDF & 0,0 & 1,6 & 1,6 \\
\hline Otros & 6,2 & $o, o$ & $\mathbf{- 6 , 2}$ \\
\hline Total & $\mathbf{1 0 0 , 0}$ & $\mathbf{1 0 o , o}$ & $/ / /$ \\
\hline
\end{tabular}

\begin{tabular}{lccc} 
Partido & $\% \mathrm{~V} 97$ & $\% \mathrm{C} 97$ & $\% \mathrm{C}$ \\
\hline \hline PD-MZA & 1,3 & 1,6 & 0,3 \\
FPN-COR & 1,3 & 1,6 & 0,3 \\
\hline CR-SJU & 0,4 & 0,8 & 0,4 \\
\hline PDP & 0,9 & 0,8 & $\mathbf{- o , 1}$
\end{tabular}

Nota: "\%V" es el porcentaje de votos obtenidos en la elección del año que correspondiente. "\%C" hace referencia al porcentaje de bancas conquistadas por partido. La abreviatura "pn" significa "partidos nacionales", mientras que "pdd" significa "partidos de distrito".

Fuente: Elaboración propia en base a Dirección Nacional Electoral (2009).

Samuels y Snyder (2001) exponen que la desproporcionalidad territorial puede tener efecto en la formación de alianzas para el Ejecutivo federal. Por los "costos" que tiene la "compra de apoyos", los distritos sobre-representados ofrecen mayor capital político que aquellos sub-representados. Así, los Ejecutivos tienen fuertes incentivos para construir coaliciones basadas en apoyos "más baratos". Cuando se observa la sobre-representación legislativa conseguida, principalmente por el PJ, se constata un alto sesgo mayoritario y partidario en Argentina. Este conjunto de fenómenos genera "bloqueo legislativo": el PJ queda con más bancas de las que “debería”, y consiguiendo la mayoría de los ejecutivos. Estos Ejecutivos tienen alto control de las legislaturas provinciales y tienen varios instrumentos para negociar con el Ejecutivo federal a través del "bloque federal" en el Legislativo (CALVO et al., 2001, 54). También en Brasil se da este fenómeno, donde partidos conservadores como el PP y el PFL, o el propio PMDB con su red clientelista, son beneficiados sistemáticamente. Sin embargo, partidos como el PDT y el PSDB sufren una disminución del porcentual de bancas en relación a los votos. Véase lo que sucede, en este sentido, en las elecciones para Deputados federais en 1994 y en 2006, en la Tabla $N^{\circ} 10$. 
Tabla 10. Brasil. SRD en la Câmara por partido (1994 y 2006)

\begin{tabular}{|c|c|c|c|c|c|c|c|}
\hline Partido & \%V 94 & $\% C 94$ & Dif. \%V-\%C & Partido & $\begin{array}{c}\% \mathrm{~V} \\
06\end{array}$ & $\%$ Co6 & $\begin{array}{c}\text { Dif. \%V- } \\
\% \mathrm{C}\end{array}$ \\
\hline PMDB & 20,3 & 20,9 & 0,6 & $\mathrm{PT}$ & 15,0 & 16,2 & 1,2 \\
\hline PSDB & 13,9 & 12,1 & $-1,8$ & PMDB & 14,6 & 17,1 & 2,5 \\
\hline PFL & 12,9 & 17,3 & 4,4 & PSDB & 13,6 & 12,7 & $-0,9$ \\
\hline PT & 12,8 & 9,6 & $-3,2$ & PFL & 10,9 & 12,7 & 1,8 \\
\hline PPR & 9,4 & 10,1 & 0,7 & PP & 7,1 & 8,2 & 1,1 \\
\hline PDT & 7,2 & 6,6 & $-0,6$ & PSB & 6,1 & 5,3 & $-\mathbf{o , 8}$ \\
\hline PP & 6,9 & 7,0 & 0,1 & PDT & 5,2 & 4,7 & $-\mathbf{0 , 5}$ \\
\hline РТB & 5,2 & 6,0 & 0,8 & РTB & 4,7 & 4,3 & $-0,4$ \\
\hline PL & 3,5 & 2,5 & $-1,0$ & PL & 4,4 & 4,4 & 0,0 \\
\hline PSB & 2,2 & 2,9 & 0,7 & PPS & 3,9 & 4,1 & 0,2 \\
\hline PcdoB & 1,2 & 1,9 & 0,7 & PV & 3,6 & 2,5 & $-1,1$ \\
\hline PSD & 0,9 & $o, 6$ & $-\mathbf{0 , 3}$ & PCdoB & 2,1 & 2,5 & 0,4 \\
\hline PPS & 0,6 & 0,4 & $-0,2$ & PSC & 1,9 & 1,8 & $-\mathbf{0 , 1}$ \\
\hline PMN & 0,6 & $o, 8$ & 0,2 & PSOL & 1,2 & $o, 6$ & $-0,6$ \\
\hline PRP & 0,5 & 0,2 & $-\mathbf{0 , 3}$ & PRONA & 1,0 & 0,4 & $-0,6$ \\
\hline PSC & 0,5 & $o, 6$ & 0,1 & PMN & 0,9 & $o, 6$ & $-0,3$ \\
\hline PRN & 0,4 & 0,2 & $-0,2$ & PTC & 0,9 & $o, 8$ & $-\mathbf{0 , 1}$ \\
\hline Otros & 1,0 & 0,3 & $-\mathbf{0 , 7}$ & PHS & 0,5 & 0,4 & $-\mathbf{0 , 1}$ \\
\hline \multirow[t]{2}{*}{ Total } & 100,0 & 100,0 & $/ / /$ & Otros & 2,4 & $o, 6$ & $-1,8$ \\
\hline & & & & Total & 100,0 & 100,0 & $/ / /$ \\
\hline
\end{tabular}

Fuente: Elaboración propia, en base a datos extraídos de Nicolau (2006).

Se acentúa que el PT, partido que durante varias elecciones sufrió negativamente con el fenómeno de la SRD (REYNOSO, 2001), presenta desempeños variados. Este partido de izquierda consigue ser beneficiado por la SRD tras llegar al Gobierno federal. Así, se pone en jaque la hipótesis de Nohlen o del propio Reynoso, que consideran que los partidos de base urbana con ideologías más progresistas son normalmente perjudicados por la SRD, porque logran buenos desempeños en los distritos mayores, sub-representados. Una explicación a esto se puede relacionar con que el PT se consolidó a nivel federal y tejió estructuras en los Estados más subdesarrollados, comenzando así a ser beneficiado por la SRD. 


\section{CONCLUSIONES}

Se observa gran cantidad de semejanzas entre ambos federalismos, al mismo tiempo en que se derrumban varios mitos. Las composiciones de los Ejecutivo y Legislativo se asemejan, dando fuerza a la figura del Presidente y al sistema bicameral. Los sistemas electoral y de partidos, aunque con características propias, también son similares. Aquí, se debe recordar la existencia de "partidos de distrito" que no sólo orbitan el ámbito provincial sino que penetran el juego federal, enviando representantes al Legislativo nacional, lo que no ocurre en el caso brasileño.

Asimismo, vemos que, mientras el sistema partidario brasileño parece estabilizarse, el sistema argentino se desestructura, tendiendo a aumentar, sin dejar claro qué puede suceder en los próximos años. Se ve, también, que ambos están transformando su estructura de voto. Brasil, con su dinámica electoral regional, pasaría a un sistema nacionalizado de partidos; por su parte, Argentina, en la dirección opuesta, parece asistir a la territorialización del voto, donde este no sigue un patrón nacional, sino una dinámica según a criterios geográficos.

Con relación a los desafíos que presentan estos federalismos, se nota una semejanza acerca de la sobre-representación distrital. Aunque la SRD en las cámaras altas sea común a la mayoría de las Federaciones (STEPAN, 1999), no puede decirse lo mismo sobre las cámaras bajas. Aquí, Argentina y Brasil se ubican como los países con mayor SRD del mundo.

El juego político al interior de estas Federaciones está desequilibrado. Afirma Tavares (1998), sobre Brasil, que la desproporcionalidad en la distribución de bancas en Deputados entre regiones y Estados determinó la coexistencia de la subrepresentación de los Estados más poblados, modernos e industrializados, con la sobrerepresentación de los Estados menos poblados y predominantemente oligárquicos. Como fue observado, la situación argentina es semejante. Las "Provincias Periféricas" -más despobladas, conservadoras, y principalmente oligárquicas- están sobrerepresentadas, mientras que las "Economías Pampeanas" - de mayor densidad poblacional y altos niveles de desarrollo económico- están sub-representadas.

Así, en ambos países, existe un equilibrio político entre las UF relacionado al criterio poblacional que tiene impacto en la arena política federal. Una vez en el poder, el partido o coalición de gobierno precisará de apoyos sólidos en el Legislativo para conseguir la aprobación de su agenda y, por los "costos" también será más fácil conseguir el apoyo de las UF periféricas, a través del envío de recursos federales, programas sociales y obras públicas. Los Gobernadores de las UF periféricas se encuentran en una posición ventajosa, a la hora de negociar recursos federales a cambio de apoyo político. 


\section{REFERENCIAS BIBLIOGRÁFICAS}

ABAL MEDINA (h.), J. M.; SUÁREZ CAO, J.; NEJAMKIS, F.. Las instituciones políticas en Brasil y Argentina: diseños similares, comportamientos distintos. Revista Argentina de Ciencia Política, Buenos Aires, n. 5-6, p. 113-134, 2002.

ARGENTINA. Constitución de la Nación Argentina. Buenos Aires, 1994. Disponible en: <http://www.jgm.gob.ar/>. Acceso en: 02/03/2008.

BENTON, A.. Presidentes fuertes, provincias poderosas: la economía política de la construcción de partidos en el sistema federal argentino. Política y Gobierno, México DF, v. 10, n. 1, ene/abr, p. 103-137, 2003.

BRASIL. Constituição da República Federativa do Brasil. Brasília, 1988. Disponible en: <http://www.planalto.gov.br/ccivil_03/Constituicao/Constituiçao.htm>. Acceso en: 02/09/2010.

CALVO, E.. Argentina, elecciones legislativas 2005: consolidación institucional del kirchnerismo y territorialización del voto. Revista de Ciencia Política, Santiago, v. 25, n. 2, agosto, p. 153-16o, 2005.

CALVO, E. et al.. Las fuentes institucionales del gobierno dividido en la Argentina: Sesgo mayoritario, sesgo partidario y competencia electoral en las legislaturas provinciales argentinas. In: CALVO, E.; ABAL MEDINA (h), J. (comps). El federalismo electoral argentino: Sobrerrepresentación, reforma política y gobierno dividido en la Argentina. Buenos Aires: EUDEBA, 2001.

CÁMARA NACIONAL ELECTORAL. Registro Nacional de Afiliados a los Partidos Políticos: Estadística Anual 2008. Disponible en: <http://www.pjn.gov.ar/o2_Central/ViewDoc.Asp?Doc=29621\&CI=INDEX100 > . Acceso en: 24/08/2009.

CARDARELLO, A.. La reelección inmediata del ejecutivo a nivel subnacional: Un estudio de tres casos. Tese (Doutorado em Ciência Política) - Programa de PósGraduação em Ciência Política, Instituto de Filosofia e Ciências Humanas, Universidade Federal do Rio Grande do Sul, Porto Alegre, 2009.

CARDOZO, N.. Brasil y Argentina: federalismo y sistema de partidos. Boletín de Política Comparada, Buenos Aires, n. 1, junio, p. 34-58, 2008

DE LUCA, M.; JONES, M.; TULA, M. I.. Back rooms or ballot boxes? Candidates nomination in Argentina. Comparative Political Studies, v. 35, n. 4, may, p. 413436, 2002.

DIRECCIÓN NACIONAL ELECTORAL. Dirección Nacional Electoral. 2009. Disponible en: <http://www.mininterior.gov.ar/asuntos_politicos_y_alectorales/dine/infogral/dine. php?idName=asuntos\&idNameSubMenu=DINE $>$. Acceso en: 31/07/2009.

KINZO, M. D. A.. Radiografia do Quadro Partidário Brasileiro. São Paulo: Fundação Konrad Adenauer, 1993.

KRAUSE, S.; PAIVA, D.. Perdas e ganhos - Lideranças políticas brasileiras e instabilidade na representação dos partidos: lógica nacional x lógica regional (1982- 
2001). In: JARDIM PINTO, C. R.; MARENCO, A. (orgs.). Partidos no Cone Sul: novos ângulos de pesquisa. Rio de Janeiro: Fundação Konrad Adenauer, 2002.

LEGISLATINA. Observatorio del Poder Legislativo en América Latina. Base de datos por país: Argentina. Salamanca, 2003a. Disponible en: $<$ http://americo.usal.es/oir/legislatina/por_pais/Argentina.pdf $>$. Acceso en: 13/05/2009.

Observatorio del Poder Legislativo en América Latina. Base de datos por país: Brasil. Salamanca, 2003b. Disponible en: <http://americo.usal.es/oir/legislatina/por_pais/Brasil.pdf>. Acceso en: 13/05/2009.

LEIRAS, M.. Los procesos de descentralización y la nacionalización de los partidos en América Latina. Trabajo presentado en el Latin American Studies Association Congress, Rio de Janeiro, 2009.

MAINWARING, S.; SHUGART, M.. Presidencialism and Democracy in Latin America. Cambridge: Cambridge University Press, 1997.

MOCCA, E.. ¿Vuelve el bipartidismo?. Página/12, Buenos Aires, El País, 14/jun., p. 23, 2009.

NICOLAU, J.. As Distorções na Representação dos Estados na Câmara dos Deputados Brasileira. Dados [online], Rio de Janeiro, v. 40, n. 3, 1997. Disponible en: <http://www.scielo.br/scielo.php?script=sci_arttext\&pid=Soo1152581997000300006\&lng=en\&nrm=iso $>$. Acceso en: 19/09/2009.

NICOLAU, J.. Base de Dados Eleitorais do Brasil (1982 - 2004). 2006. Disponible en: <http://jaironicolau.iuperj.br/banco2004.html>. Acceso en: 25/05/2009.

PERES, P. S.. Sistema partidário e instabilidade eleitoral no Brasil. In: JARDIM PINTO, C. R.; MARENCO, A. (orgs.). Partidos no Cone Sul: novos ângulos de pesquisa. Rio de Janeiro: Fundação Konrad Adenauer, 2002.

REYNOSO, D.. Distritos y escaños en Brasil: antecedentes, diagnóstico y consecuencias partidarias del malaporcionamiento. Política y Gobierno, México DF, v. VIII, n. 1, p. 167-191, $1^{\circ}$ semestre, 2001..

REYNOSO, D. Bicameralismo y sobre-representación en Argentina en perspectiva comparada. Revista SAAP, Buenos Aires, v. 2, n. 1, p. 69-94, diciembre, 2004.

RODRÍGUEZ, C.. República Argentina: Elecciones Presidenciales, Legislativas y Provinciales 2007. Disponible en: $<$ http://americo.usal.es/oir/Opal/elecciones/ARGENTINA.pdf>. Acceso en: 30/07/2009.

ROMA, C.; BRAGA, M. S.. Sistema partidário, eleições e a questão federativa no Brasil (1986-2000). In: JARDIM PINTO, C. R.; MARENCO, A. (orgs.). Partidos no Cone Sul: novos ângulos de pesquisa. Rio de Janeiro: Fundação Konrad Adenauer, 2002.

SAMUELS, D.; SNYDER, R. El valor de un voto: una perspectiva comparada sobre la desproporcionalidad territorial. En: CALVO, E.; ABAL MEDINA (h.), J. M. (comps). El federalismo electoral argentino: Sobrerrepresentación, reforma política y gobierno dividido en la Argentina. Buenos Aires: EUDEBA, 2001. 
STEPAN, A.. Para uma nova análise comparativa do federalismo e da democracia: federações que restringem ou ampliam o poder do demos. Revista Dados, Rio de Janeiro, v. 42, n. 2, abril, p. 197-251, 1999.

TAVARES, J. A. G.. O sistema político brasileiro. En: ROJO, R. (org.). Instituições políticas comparadas dos países do Mercosul. Rio de Janeiro: Editora FGV, 1998.

TRIBUNAL SUPERIOR ELEITORAL. Tribunal Superior Eleitoral. 2010. Disponible en: <http://www.tse.gov.br/internet/index.html>. Acceso en 10/10/2010. 